\title{
Advantages of Using Quantitative Shape Descriptors in Protocols for Plant Cultivar and Postharvest Product Quality Assessment
}

\author{
Da-Wen Sun • Corrado Costa • Paolo Menesatti
}

Received: 19 October 2011 / Accepted: 19 October 2011 /Published online: 5 November 2011

(C) Springer Science+Business Media, LLC 2011

\begin{abstract}
Shape of plant and agricultural products is one of the most important factors for classification and grading. Shape is crucial to species, cultivar and variety identification and authenticity, commercial quality and organoleptic properties assessment. The need to quantitatively assess shape has always been thwarted with the multivariate and multidimensional complexity of shape itself. For this reason, only agricultural product size parameters (e.g. length, width, volume or ratios) are widely measured as criteria for quality grading in the industry. However, the subjective appearance of such products is a primary criterion in making purchasing decisions at retail outlets (Kays 1991). Typically, the appearance of products is visually evaluated by consumers based on size, shape, form, colour, freshness and the absence of visual defects. All these characteristics contribute to the overall appearance and are used as an important quality indicator throughout the value chain, from production and processing to storage, marketing and purchase by the end user. Among appearance features of agricultural products, shape plays a central role (Costa et al. 2011). Shape is an important factor in
\end{abstract}

\section{D.-W. Sun $(\bowtie)$}

Food Refrigeration \& Computerised Food Technology,

School of Biosystems Engineering,

University College Dublin, National University of Ireland,

Agriculture \& Food Science Centre,

Belfield,

Dublin 4, Ireland

e-mail: dawen.sun@ucd.ie

URL: http://www.ucd.ie/refrig; http://www.ucd.ie/sun

\section{Costa $\cdot$ P. Menesatti}

CRA-ING (Agricultural Engineering Research

Unit of the Agriculture Research Council),

Via della Pascolare, 16,

00015 Monterotondo, Roma, Italy distinguishing among different phenotypes (Xiao et al. 2008) or among the same cultivar depending on farming conditions (McKenzie 1971). For example, gross irregularities in the shape of fruit and vegetables are a critical rejection factor in consumer decision making (Cubero et al. 2011). While shape is an essential parameter, little attempts have been made to quantify it until recently. Recent research advances that combine imaging, morphometrics and multivariate analyses allow the development of quantitative shape measurement protocols such as automated shape processing system (Costa et al. 2011).

While the use of shape in an automated sorting system has many potential applications, it is suggested to focus on its use in the context of the certification systems based on the technical protocols of the International Union for the Protection of New Varieties of Plants, Community Plant Variety Office or those for the three EU schemes known as protected designation of origin (PDO), protected geographical indication (PGI) and traditional speciality guaranteed (TSG). These protocols do not consider shape as a quantitative variable, and phenotype and variety assessment and/or certification is mainly based on general semantic and qualitative shape descriptors set out in visual charts. Some recent studies have showed inconsistencies of shape descriptions among different semantic or visual charts that are currently in use, such as the International Plant Genetic Resources Institute (IPGRI 1999), citrus industry (Hodgson 1967) and instrumental measurements (Costa et al. 2009; Antonucci et al. 2011).

In the last few years, advances in food optoelectronic detection, computational hardware and imaging algorithm developments coupled with the second generation multivariate modelling approaches has led to the technical feasibility to measure different shape features and variation 
in a quantitative fashion. To date, different methods for quantitative shape evaluation have been suggested to distinguish phenotypes or varieties of agricultural products (Costa et al. 2011). Basic shape descriptors, such as perimeter, circularity, roundness, symmetry and ratios between descriptors are some of the most common features extracted to classify or identify products (Blasco et al. 2009). Complex outline-based shape descriptors, such as those based on Fourier analysis (Kuhl and Giardina 1982), have the key advantage of being scale and rotation invariant, and therefore have also been successfully used to assess the differences among leaves, fruits, vegetables, kernels, roots and flowers.

In relation to this, the advanced quantitative shape description method possesses the following advantages: (1) it allows classifying the shape of each single object (i.e. fruit or vegetables for example) within established groups, (2) it can describe the general object shape as well as the shape of particular regions such as the apex and the base, (3) it can quantitatively measure the shape variability among different varieties, (4) it can graphically report the cultivar mean shape and its variability, (5) it is faster than subjective attribution based on semantic or visual charts and (6) it allows the development of automatic and objective systems based on computer vision to grade and sort products by shape. All these advantages could lead to the creation of an open access databases for different types of shapes. Due to the above advantages in using quantitative shape descriptors in quality assessment for plant variety and postharvest product, the above-mentioned institutions may include quantitative shape descriptors in their protocols for automatic plant phenotyping.

In addition, further research on the topic could provide innovative technical supports to national and international production and trade of plants and agricultural products. Such research could benefit breeders and horticulturists in defending the cultivar rights, addressing varietal selection to the consumer preferences and more generally enhancing competitiveness. Such research could also benefit legislators and control bodies along the supply chain in making the protocols for monitoring and certification more effective, providing a greater transparency and competition, granting the traceability with positive spillover effects in food security and identifying fraudulent products. Furthermore, such research could benefit consumers with greater quality assurance in terms of genetic origin and organoleptic characteristics.

\section{References}

Antonucci, F., Costa, C., Pallottino, F., Paglia, G., Rimatori, V., De Giorgio D., et al. (2011) Quantitative method for shape description of almond cultivars (Prunus amygdalus Batsch). Food and Bioprocess Technology (in press), doi: 10.1007/ s11947-010-0389-2.

Blasco, J., Aleixos, N., Cubero, S., Gómez-Sanchis, J., \& Moltó, E. (2009). Automatic sorting of satsuma (Citrus unshiu) segments using computer vision and morphological features. Computers and Electronics in Agriculture, 66, 1-8.

Costa, C., Menesatti, P., Paglia, G., Pallottino, F., Aguzzi, J., Rimatori, V., et al. (2009). Quantitative evaluation of Tarocco sweet orange fruit shape using opto-electronic elliptic Fourier based analysis. Postharvest Biology and Technology, 54, 38-47.

Costa, C., Antonucci, F., Pallottino, F., Aguzzi, J., Sun, D.-W., \& Menesatti, P. (2011). Shape analysis of agricultural products: a review of recent research advances and potential application to computer vision. Food and Bioprocess Technology, 4, 673-692.

Cubero, S., Aleixos, N., Moltó, E., Gómez-Sanchis, J., \& Blasco, J. (2011). Advances in machine vision applications for automatic inspection and quality evaluation of fruits and vegetables. Food and Bioprocess Technology, 4, 487-504.

Hodgson, R. W. (1967). Horticultural varieties of citrus. In W. Reuther, H. J. Webber, \& L. D. Bachelor (Eds.), The citrus industry (Vol. 1, pp. 431-591). Berkley: University of California.

IPGRI (1999) Descriptors for Citrus. International Plant Genetic Resources Institute, Rome, Italy. ISBN 92-9043-425-2.

Kays, S. J. (1991). Postharvest physiology of perishable plant products. New York: Van Nostrand Reinholt.

Kuhl, F. P., \& Giardina, C. R. (1982). Elliptic Fourier features of a closed contour. Computer Graphics and Image Processing, 18, 236-258.

McKenzie, D. W. (1971). A survey of shape variation in some New Zealand apples. New Zealand Journal of Agricultural Research, 14, 491-498.

Xiao, H., Jiang, N., Schaffner, E., Van der Stockinger, E. J., \& Knaap, E. (2008). A retrotransposon-mediated gene duplication underlies morphological variation of tomato fruit. Science, 319, 1527-1530. 